Special Issue "Using Econometrics for Assessing Economic Models"

Editor: Katarina Juselius

\title{
The New Keynesian Phillips Curve Tested on OECD Panel Data
}

\author{
Roger Bjørnstad \\ Statistics Norway \\ Ragnar Nymoen \\ University of Oslo
}

\begin{abstract}
:
Using a panel data set for OECD countries we replicate the typical features of the New Keynesian Phillips curve models (NPCs) that have been estimated on country data. While this corroborates the NPC also on the macro panel data set, a different conclusion is reached when we test whether the NPC encompasses an existing model of inflation which is without feed-forward terms, but which allows for other adjustment factors than the NPC. We find that the NPC's expected rate of future inflation and real marginal costs are weak explanatory variables, and that their statistical significance in the typical NPC is due to correlation with the equilibrium correction terms that are implied by the existing inflation model. Our results are in line with the relatively few encompassing studies that exist on country and area data.
\end{abstract}

\section{JEL: C23, C52, E12, E31}

Keywords: New Keynesian Phillips curve; forward-looking price setting; panel data model; encompassing

\section{Correspondence:}

Roger Bjørnstad, Statistics Norway, Research Department, N-0033 Oslo, Norway.

E-mail: roger.bjornstad@ssb.no

The authors would like to thank two anonymous referees, and the editor Katarina Juslius, for their constructive and detailed comments, and Sunil Sapra for his comments on the webpage of Economics: The Open-Access, Open-Assessment E-Journal. Many thanks also to Pål Boug, David F. Hendry, Erling Holmøy, Grayham E. Mizon, Sunil Sapra and Terje Skjerpen for comments and discussion. The numerical results were produced by EViews 5.1, Quantitative Micro Software (2005), PcGive 10, Hendry and Doornik (2001) and Doornik and Hendry (2001), and RATS v. 5.00, Doan (2000). 


\section{Introduction}

The hybrid New Keynesian Phillips Curve, hereafter NPC, is an integral part of the standard model of monetary policy. This position is due to its microeconomic foundation, as laid out in Clarida et al. (1999), but also the successful estimation of NPC models on time series data from different countries. In particular, the studies of Galí and Gertler (1999, henceforth GG), and Galí, Gertler and López-Salido (2001, henceforth GGL) give empirical support for the NPC, in the form of correctly signed coefficients and a reasonable good data fit - using US as well as euro-area data. Rudd and Whelan (2005) and Linde (2005) criticize several aspects of the estimation and inference procedures used by GGL, but this line of critique is rebutted in GGL (2005), who re-assert that the NPC, in particular the dominance of forward-looking behavior, is robust to choice of estimation procedure and specification bias. However, there are several other reasons to be sceptical to the NPC's status as a proven model of inflation.

First, model evaluation entails consideration of all the properties and implications of a chosen or maintained interpretation of the correlations, not only the favourable ones, and also mindfulness of any alternative hypotheses and explanations of the estimates obtained. Specifically, the issue of encompassing, i.e., whether the NPC model can explain the properties of earlier models, is not investigated formally in the series of papers by GG and GGL.

Following Hendry (1988), the encompassing principle is particularly useful for testing models with rational expectations against models with subjective or 'backwardlooking' expectations. In line with this, recent research on euro-area data, as well as on time series from the UK and Norway, shows that the hybrid NPC model fails to meet the encompassing principle, see Bårdsen et al. (2004), Bårdsen et al. (2005, Ch. 7) and Boug et al. (2006). In this paper we take that testing strategy to a panel data set. We also extend the earlier encompassing tests of the NPC by formulating a framework that identifies a larger set of encompassing implictions of the NPC relative to existing models that are consistent with monopolistic competition, but not necessary with rational expectations.

Lack of independent evidence of the claimed robustness of the NPC is another reason for concern. Bårdsen et al. (2004) show that the euro-area NPC estimated by GGL is not robust to very detailed changes in the GMM estimation, i.e., changes that should have negligible impact under the null that the NPC is a valid representation of the inflation process. ${ }^{1}$

Finally, as pointed out by Fuhrer (2006), there is an issue of internal inconsistency in the NPC literature. He shows that the typical NPC fails to deliver the intended result that inflation persistence is 'inherited' from the persistence of the forcing variable. Instead, the derived inflation persistence, using estimated NPCs, turns out to be completely dominated by 'intrinsic' persistence (due to the accumulation of disturbances of the NPC equation). Fuhrer concludes by stating that the evidence that have been reported in favour of the NPC implies that the lagged inflation rate is not a 'second order add on to the underlying optimizing behavior of price setting

\footnotetext{
${ }^{1}$ The non-robustness due to details in the GMM estimation relates to the significance of the real marginal cost term, see also Bårdsen et al. (2005, Ch. 7).
} 
firms, it is the model'.

In this paper, we estimate the hybrid NPC on a panel data set from OECD countries assuming homogenous derivative coefficients. This pooled estimator is biased if homogeneity is falsely imposed, but it is more efficient and it has less small sample bias than would have been the case if the model was estimated for each country separately. However, the main motivation for considering a pooled estimator stems from the observation that the microfoundations of the NPC model abstract from the institutional and historical idiosyncrasies of individual countries, and that this may explain why the NPC is found to be inferior to models that are specified to explain exactly those features. If this is correct, the NPC can be expected to perform better as a model of "average" price dynamics for a panel of countries, than in contests with country specific and econometrically well fitting inflation models.

Our first finding in this paper show that the typical NPC equation stands its ground very well on the OECD data set, in particular the dominance of forwardlooking behavior in price setting is confirmed. This result indicates that if the pooled estimator is biased, the bias is small. The second finding is that when the evidence represented by existing models of price setting is taken into account, the strong support for the NPC model disappears. This does not contradict the first finding, but shows that the NPC fails on the encompassing test. For example, the coefficient of the forward rate becomes statistically insignificant and is numerically close to zero. Exactly this result is predicted by dynamic imperfect competition models of inflation, henceforth ICM, see Bårdsen et al. (2005, Chapter 5-6) and Bårdsen and Nymoen (2003).

We leave for further work to investigate closer the poolability of the coefficients, and the optimal specification of the OECD panel ICM model, but concludes that the standard NPC model both in 'pure' and hybrid form, is encompassed by ICMs with well defined equilibrium correction terms. ICMs incorporate the theoretical ideas of monopolistic competition within the equilibrium-correction inflation model of Sargan (1980) and Nymoen (1991). Basically, the ICM framework predicts that the significance of the inflation rate one period ahead in estimated NPC models, is a result of omitted variable bias. In the simplest case, the omitted variable is the equilibrium-correction variable, i.e. a linear combination of unit labour costs and the real exchange rate. Hence, the ICM's encompassing implications parallels Yule's analysis of spurious correlations in economics; the correlation between two variables (here: current and future inflation) being related to some third variable (here: a well specified equilibrium correction term). ${ }^{2}$ Conversely, we show below that the equilibrium correction variables suggested by the ICM can be rationalized under the hypothesis that the NPC holds. It is then straightforward to test the null hypothesis that the NPC restrictions hold using likelihood ratio tests.

The paper is organized as follows: In section 2, we give, as a background, GGL's view about the 'state of the NPC' as a theoretically derived model of inflation with desirable empirical properties. We also explain our own stance, namely that the lack of evidence of encompassing is a signal that the NPC, although brilliantly derived as a theoretical model, should not be automatically accepted as the new

\footnotetext{
${ }^{2}$ See Aldrich (1995) for an overview of Udny Yule's work on spurious correlations.
} 
standard model of supply side of macroeconomic models used for policy analyses, see Bårdsen and Nymoen (2008). In section 3, we explain the framework for our encompassing oriented assessment of the NPC on OECD panel data, and section 4 presents the data set and discusses some pertinent econometric issues. The results of the econometric tests are given in section 5 . Section 6 concludes.

\section{The Empirical Status of the NPC}

The hybrid NPC is given as

$$
\Delta p_{t}=\underset{\geq 0}{a^{f}} \Delta p_{t+1}^{e}+\underset{\geq 0}{a^{b} \Delta p_{t-1}}+\underset{\geq 0}{b} w s_{t}
$$

where $\Delta p_{t+1}^{e}$ is expected inflation one period ahead, conditional on the information available in period $t-1 .^{3}$ Lower case letters indicate that the variable is measured in logs, and the third variable in (1) is the logarithm of the wage-share, ws, which is the preferred operational definition of firms' marginal costs of production. ${ }^{4}$.

The 'pure' NPC is specified without the lagged inflation term $\left(a^{b}=0\right)$. In the case of the pure NPC, Roberts (1995) has shown that several New Keynesian models with rational expectations have (1) as a common representation - including the models of staggered contracts developed by Taylor $(1979,1980)^{5}$ and Calvo (1983), and the quadratic price adjustment cost model of Rotemberg (1982). The rationale for allowing $a^{b}>0$ is that the theory applies to a (significant) portion of price adjustments in period $t$, but not to all. Hence, in each period, a share of the overall rate of inflation is determined by last period's rate of inflation, for example because of backward-looking expectations.

The main references supporting the NPC are the articles by GG and GGL mentioned above who find that the typical NPC estimation gives the following results:

1. The two null hypotheses of $a^{f}=0$ and $a^{b}=0$ are firmly rejected both individually and jointly.

2. The hypothesis of $a^{f}+a^{b}=1$ is typically not rejected at conventional levels of significance, although the estimated sum is usually a little less than one.

3. The estimated value of $a^{f}$ is larger than $a^{b}$, hence forward-looking behavior is dominant. $a^{b}$ is usually estimated in the range of 0.2 to 0.6 .

4. When real marginal costs are proxied by the wage share, the coefficient $b$ is positive and significantly different from zero at conventional levels of significance.

\footnotetext{
${ }^{3}$ To be precise, $\Delta p_{t}^{e}=\mathrm{E}\left(\Delta p_{t+1} \mid \mathcal{I}_{t-j}\right)$ where $\mathrm{E}\left(\Delta p_{t+1} \mid \mathcal{I}_{t-j}\right)$ denotes the mathematical expectation given information available in time period $t-j$. It has become custom to assume that $j=0$.

${ }^{4}$ Other close-at-hand measures are the output-gap or the rate of unemployment. However it is the wage-share which most often yields the expected sign on the estimated coefficient of marginal costs, see Gali et al. (2005). However, also for the wage-share definition, the results are non-robust to minor changes in estimation methodology, see Bårdsen et al. (2004).

${ }^{5}$ The overlapping wage contract model of sticky prices is also attributed to Phelps (1978).
} 
Critics of the NPC have challenged the robustness of all four typical traits, but with different emphasis and from different perspectives. The inference procedures and estimation techniques used by GG and GGL have been criticized by Rudd and Whelan (2005) and others, but GGL (2005) show that their results remain robust. However, the statistical adequacy of the NPC for US and euro area data is also brought into doubt by the results in Fanelli (2008) and Juselius (2007, Ch III) based on the vector autoregressive regression model.

Bårdsen et al. (2004) assessed the NPC from another perspective, namely that of encompassing. For several countries, inflation models existed before the NPC model, and it is generally advisable to test a new model, the NPC in this case, against such models. Bårdsen et al. (2004) concentrate on the dynamic imperfect competition model (ICM) of wage and price setting. Using data for the euro area Bårdsen et al. (2004) find that the NPC model fails to account for the properties of the dynamic ICM model. Conversely, they show that the ICM class of models can successfully explain the seemingly robust features of the NPC.

In the next section we develop the encompassing analysis further by showing that both the NPC and the ICM can be written as price adjustment models in equilibrium correction form. However, compared to the dynamic ICM, the NPC is a highly restrictive equilibrium correction model. A test for the validity of these restrictions is also an encompassing test between the two rival models. In section 5 we report the results of such tests using a panel of OECD countries. ${ }^{6}$

There is no suggestion in the theory underlying the NPC about how we should choose the time period $t$ in equation (1), as month, quarter or year. The applications and tests on country data just cited use quarterly data, whereas with panel data the annual period is the only practical choice. This give rises to the questions of temporal aggregation consequences and of comparison of results based on the two periodicities. However, Galí and Gertler (1999) noted that prior to their work on quarterly data the only successful estimation of NPCs had used annual data, indicating that if anything, the annual frequency favours the NPC. Consistent with this view we show below that the typical features 1-4 above are replicated on our annual data set, indicating robustness with respect to temporal aggregation.

\section{An Encompassing Framework for Competing Theories of Price Setting}

In this paper, we make use of data from 20 OECD countries, so the closed economy NPC in (1) is a limitation. Batini et al. (2005) have derived an open economy NPC from theoretical principles, showing that the main theoretical content of the NPC generalizes, but that consistent estimation of the parameters $a^{f}$, $a^{b}$ and $b$ requires that the model is augmented by variables which explain inflation in the

\footnotetext{
${ }^{6}$ Our focus is the encompassing capability of the NPC vis-a-vis, the European tradition of equilibrium correction based inflation modelling. Equally interesting is the testing of the NPC against the North American Phillips-curves, see Gordon (1997) which pre-dates the US data NPC of Galí and Gertler (1999) by several decades, yet GGL exclude that information from the assessment of their new model.
} 
open economy case. Hence, the open economy NPC (OE-NPC) is

$$
\Delta p_{t}=\underset{\geq 0}{a^{f} \Delta p_{t+1}^{e}}+\underset{\geq 0}{a^{b} \Delta p_{t-1}}+\underset{\geq 0}{b} w s_{t}+c x_{t}
$$

where $x_{t}$, in most cases a vector, contains the open-economy variables, and $c$ denotes the corresponding coefficient vector. The change in the real import price, $\Delta\left(p i_{t}-p_{t}\right)$ in our notation, is the single most important open economy augmentation of the NPC. The results in Batini et al. (2005) are, broadly speaking, in line with GG's and GGL's properties 1.-4., but as noted, those properties are not robust when tested against the existing UK model in Bårdsen et al. (1998).

To derive testable implications of the NPC on our country data set we make use of the identity

$$
w s_{t} \equiv u l c_{t}-p d_{t}
$$

where ulc denotes unit labour costs (in logs) and $p d$ is the log of the price level on domestic goods and services. We let $(1-\gamma)$ denote a constant import share, and define the aggregate price by the definition:

$$
p_{t} \equiv \gamma p d_{t}+(1-\gamma) p i_{t}
$$

If we solve for $p d$, insert in (3) and re-write, we obtain the following equation for the wage-share:

$$
w s_{t}=-\frac{1}{\gamma}\left[p_{t-1}-\gamma u l c_{t-1}-(1-\gamma) p i_{t-1}\right]+\Delta u l c_{t}-\frac{1}{\gamma} \Delta p_{t}+\frac{1-\gamma}{\gamma} \Delta p i_{t} .
$$

We can then re-write the open economy NPC as

$$
\begin{aligned}
\Delta p_{t} & =\frac{a^{f}}{\left(1+\frac{b}{\gamma}\right)} \Delta p_{t+1}^{e}+\frac{a^{b}}{\left(1+\frac{b}{\gamma}\right)} \Delta p_{t-1}-\frac{b}{(\gamma+b)}\left[p_{t-1}-\gamma u l c_{t-1}-(1-\gamma) p i_{t-1}\right] \\
& +\frac{\gamma b}{(\gamma+b)} \Delta u l c_{t}+\frac{b(1-\gamma)}{(\gamma+b)} \Delta p i_{t}+\frac{\gamma c}{(\gamma+b)} x_{t}
\end{aligned}
$$

or

$$
\begin{aligned}
\Delta p_{t} & =\alpha^{f} \Delta p_{t+1}^{e}+\alpha^{b} \Delta p_{t-1}+\beta\left(u l c_{t-1}-p_{t-1}\right)-\beta(1-\gamma)\left(u l c_{t-1}-p i_{t-1}\right) \\
& +\beta \gamma \Delta u l c_{t}+\beta(1-\gamma) \Delta p i_{t}+\psi x_{t}
\end{aligned}
$$

where we have conveniently defined $\alpha^{f}, \alpha^{b}, \beta$ and $\psi$ as new coefficients. This equation brings out that the NPC has an interpretation as an equilibrium correction model (ECM), of the price level, see Sargan (1980) and Nymoen (1991), but with two important remarks. First, the usual ECM for inflation is extended by the inclusion of the forward-looking term $\Delta p_{t+1}^{e}$. Second, the econometric ECM is restricted since the 
coefficients of $\Delta u l c_{t}, \Delta p i_{t}$ and the ECM terms, $\left(u l c_{t-1}-p_{t-1}\right)$ and $\left(u l c_{t-1}-p i_{t-1}\right)$, are restricted to be functions of $b$ and $\gamma$.

(6) assumes a constant import share which may be too stylized for many purposes. However, how this restriction affects the comparison between rival models of inflation is not clear a priori, and in section 5 we take care to show that it does not tilt the evidence against the NPC in the encompassing test.

As mentioned above, an alternative model for price formation is the imperfect competition model, ICM, where prices are set as a mark-up over unit labour cost and where the mark up depends on relative prices:

$$
p d=m_{0}-m_{1}(p d-p i)+u l c,
$$

where $0 \leq m_{1} \leq 1$. By using (4) we get

$$
p=\mu_{0}+\mu_{1} u l c+\left(1-\mu_{1}\right) p i
$$

where $\mu_{1}=\frac{\gamma}{1+m_{1}}$ and $\mu_{0}=m_{0} \mu_{1}$. Due to for example shocks, incomplete information and adjustment costs, prices are rarely at this optimal level. Therefore it has become standard to present the ICM in equilibrium correction form, where (8) is used to define the equilibrium correction variable, and where variables that are likely to be important in the short run are also included in the model. For simplicity, we assume that the dynamic part of the NPC is valid, and therefore include the same variables also in the equilibrium correction model, which then becomes:

$$
\begin{aligned}
\Delta p_{t} & =\alpha^{f} \Delta p_{t+1}^{e}+\alpha^{b} \Delta p_{t-1}+\beta_{1}\left(u l c_{t-1}-p_{t-1}\right)+\beta_{2}\left(u l c_{t-1}-p i_{t-1}\right) \\
& +\beta_{3} \Delta u l c_{t}+\beta_{4} \Delta p i_{t}+\psi x_{t} .
\end{aligned}
$$

A comparison of the two models, the OE-NPC in (6) and equation (9), reveals that the OE-NPC is a special case of the (9). The standard ICM, without the lead in inflation, is also a special case of (9). Therefore we will refer to (9) as the minimum nesting model or the encompassing model, cf Hendry (1995, ch 14.6). The OE-NPC in (6) implies the following restrictions on the coefficients in (9): $H_{0}^{a}: \beta_{3}=\beta_{1}+\beta_{2}$ and $H_{0}^{b}: \quad \beta_{4}=-\beta_{2}$. Hence, the rejection of $H_{0}^{a}$ and/or $H_{0}^{b}$ are not consistent with OE-NPC parsimoniously encompassing model (9). The same applies if $H_{0}^{c}$ : $\alpha^{f}=0$ cannot be rejected statistically based on estimation of (9): this test-outcome is inconsistent with the main assumption of the NPC, namely that a significant proportion of price setters are forward looking in the rational expectations sense. Finally $H_{0}^{d}: \alpha^{b}=0$ can also be tested using (9).

The tests of the significance of the forward and lagged inflation terms, $H_{0}^{c}: \alpha^{f}=0$ and $H_{0}^{d}: \alpha^{b}=0$, are basically panel data versions of the usual econometric assessment of the NPC on country (or area) data referred to above, GG and GGL in particular. The two former hypotheses $H_{0}^{a}$ and $H_{0}^{b}$, which capture the implied NPC restrictions for the leads and lags of $u l c$, have so far not been considered systematically. However, as noted above, OE-NPC models are usually specified with the rate of change in the real import price as one of the elements in $x_{t}$. Equation (9) is consistent with that interpretation, the only caveat applies to $\beta_{4}$ and $H_{0}^{b}$, since $\beta_{4}=-\beta_{2}$ no longer follows logically from the NPC. This is because $\beta_{4}$ is a compos- 
ite parameter also when the NPC is the valid model. For that reason, our focus in section 5 will be on hypotheses $H_{0}^{a}, H_{0}^{c}, H_{0}^{d}$, and not on $H_{0}^{b}$.

The ICM implies fewer testable restrictions on the nesting model in (9). The ICM does however require that $\beta_{1}>0$ and $0>\beta_{2}>-\beta_{1}$. Subject to this, the standard ICM, without a lead-term parsimoniously encompasses model (9) if $H_{0}^{c}$ : $\alpha^{f}=0$ is not rejected statistically.

Nesting of the two rivaling models in an encompassing model is convenient for formal testing of parsimonious encompassing. If the encompassing test reveals that the ICM is a congruent model, it predicts the misspecification of the NPC model as showed in -Bårdsen et al. (2004). In particular, $\alpha^{f}$ will then be biased upwards. The reason for this is that the omitted variables, $\left(u l_{i, t-1}-p_{i, t-1}\right)$ and $\left(u l c_{i, t-1}-p i_{i, t-1}\right)$, are positively correlated with both $\Delta p_{t}$ and $\Delta p_{t+1}^{e}$. Inclusion of $\left(u c_{i, t-1}-p_{i, t-1}\right)$ and $\left(u l c_{i, t-1}-p i_{i, t-1}\right)$ in the list of instruments used when estimating the NPC will not solve this problem with bias, although it will reduce the problem of weak instruments.

Statistical significance of Sargan's (1964) test for the validity of overidentifying instruments, dubbed $\chi_{\text {ival }}^{2}$ in table 2 below, is a sign that bias due to omitted variables may be an issue, since that test is interpretable as a test of whether the structural equation (i.e., the NPC) parsimoniously encompass the implied unrestricted reduced form, where all the instruments are included as explanatory variables in the model. Hence, if estimation of (2) gives the expected signs and magnitudes of $a^{f}$ and $a^{b}$ at the same time as $\chi_{\text {ival }}^{2}$ is significant, and the estimated value of $a^{f}$ is reduced when $\left(u l c_{i, t-1}-p_{i, t-1}\right)$ and $\left(u l c_{i, t-1}-p i_{i, t-1}\right)$ are moved from the list of instruments and instead are included in the inflation equation, the NPC is likely to be misspecified. Bårdsen et al. (2005, Ch 7) report such a constellation of evidence for three different data sets: the euro area, the UK and Norway. Below we show that a similar constellation is found for the panel of OECD data.

Finally, the misplacement of explanatory variables in the list of instruments will also lead to autocorrelated residuals in the NPC equation. This aspect of encompassing may be difficult to detect though, since a first order moving average process in the NPC residuals are consistent with that model, due to replacement of the expected lead with the actual lead.

\section{Data and Econometric Issues}

We use a data set for annual wages and prices for 20 OECD countries. The data in the analysis are retrieved from OECD's Main Economic Indicator (MEI) database. The definitions and data sources are given in appendix A, but we note that while almost all previous papers use data for the manufacturing sector we use the OECD unit labour cost index that covers the whole economy. The import price index is the ratio of the value and the volume of imported goods and services. Furthermore, we measure the endogenous inflation rate with the change in the consumer price index. The panel is unbalanced, but for most of the countries the time period is 1960-2004. Because of one lead and one lag we loose the first and last observations.

As a benchmark model we first estimate the NPC model (2) with the following variables in the $x$ vector: the rate of change in the oil price in US\$ $\left(\Delta p o_{t}\right)$ that 
captures cost shocks common to the countries in the panel, the change in the indirect tax rate $\left(\Delta V A T_{i, t}\right)$ and the change in the real import price $\Delta\left(p i_{i, t}-p_{i, t}\right) .{ }^{7}$ The oil price .

We then estimate the open economy inflation equation (9) that brings out the relationship between the NPC model and the dynamic ICM model, which we repeat here as:

$$
\begin{aligned}
\Delta p_{i, t} & =\theta_{i}+\alpha^{f} \Delta p_{i, t+1}^{e}+\alpha^{b} \Delta p_{i, t-1}+\beta_{1}\left(u l c_{i, t-1}-p_{i, t-1}\right) \\
& +\beta_{2}\left(u l c_{i, t-1}-p i_{i, t-1}\right)+\beta_{3} \Delta u l c_{i, t}+\beta_{4} \Delta p i_{i, t} \\
& +\psi_{1} \Delta p o_{t}+\psi_{2} \Delta V A T_{i, t}+\varepsilon_{i, t}
\end{aligned}
$$

where $\theta_{i}, i=1, \ldots, N$, is country-specific fixed effects and $\varepsilon_{i, t}$ is a stochastic error term. This model is denoted Minimum nesting model in the next section. As we have seen above, the validity of the NPC hinges not only on the significance of the forward term (rejection of $H_{0}^{c}: \alpha^{f}=0$ ), but also on $H_{0}^{a}: \beta_{3}=\beta_{1}+\beta_{2}$ not being rejected. The estimation of (10) in a panel like ours might be associated with various econometric problems. These problems are discussed next.

First, the presence of $\Delta p_{t+1}^{e}$ in the model causes two econometric problems. The first is a relatively minor one, and arises because estimation proceeds by substitution of $\Delta p_{t+1}^{e}$ by the observable $\Delta p_{t+1}$. In general this induces a moving average disturbance term in the estimated model, see Blake (1991). We tackle this problem by the use of GMM estimation with (hopefully) valid instruments. The second problem is more fundamental as models with forward-looking rational expectation terms are difficult to identify, see Pesaran (1987) and Mavroeidis (2004). In brief, one implication of rational expectations is that valid instruments may also be weak instruments. As a practical solution, we include the 2. order lag of variables like inflation in the instrument list. This will contribute to identification if the marginal model of e.g., $u l c_{t}$ does not depend on $\Delta p_{t-1}$. Other available variables may also be used as instruments. For example, since $\Delta u l c_{t}$ is on the right hand side, we can use lags of rates of unemployment as instruments since we do not expect the rate of unemployment to affect inflation through other channels than unit labour costs. The same line of reasoning motivates that variables measuring employment protection and the unemployment benefit replacement ratio can be used as instruments. The full set of instruments is given in connection with the econometric results in the section below.

Second, Nickell (1981) shows that OLS estimation may be inconsistent when applied to models that include fixed effects and a lagged dependent variable. The bias is of the order $1 / T$, where $T$ is the time dimension of the panel. In our case the time dimension varies from 21 to 37 , therefore it is likely that the 'Nickell bias' will be very small. Moreover, this is largely confirmed by Judsen and Owen (1999) who show that OLS estimation of dynamic fixed effects models perform well for $T=30$, i.e. with a $T$ dimension similar to ours. Even when $T=20$, the fixed effects estimator was almost as good as the alternatives (GMM and Anderson-Hsiao).

Third, the pooled panel data regression is valid only under the assumption that

\footnotetext{
${ }^{7}$ Of course, since we normalize on $\Delta p_{t}$, it is nominal import price growth that appears on the right-hand-side of the estimated equation.
} 
Table 1: Pedroni (1999) Panel Cointegration Tests. Heterogeneous Intercepts Included ( $\mathrm{p}$-values in parentheses)

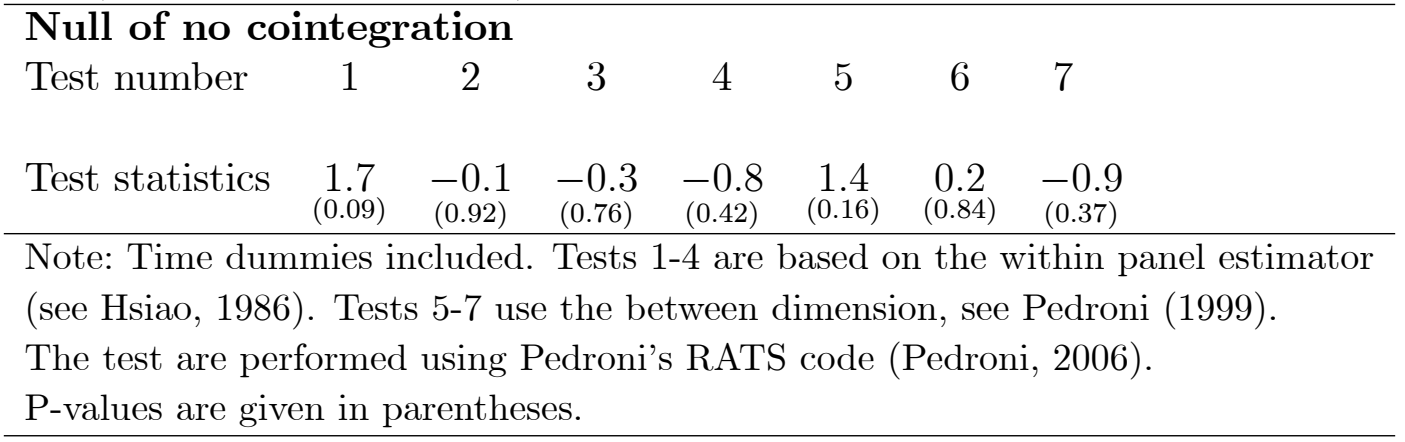

the slope coefficients are homogeneous across countries. As shown by Pesaran and Smith (1995), if homogeneous coefficients are falsely imposed, the pooled estimator is inconsistent even if $T$ approaches infinity. However, as pointed out by (Baltagi, 1995, Ch. 4) the pooled model can yield more efficient estimates at the expense of bias, and one must therefore balance the two concerns. Since the estimated panel data coefficients have the same magnitude as in other country-specific studies, we believe the bias to be relatively small.

Fourth, since we have relatively long time series, a stance need to be taken on the degree of integratedness and possible cointegration. Panel data test of unit root tests reveal that our times series of consumer price, inmport price and unit labour cousts can be regarded as non-stationary as well, see Bjørnstad and Nymoen (2008, Table 1) for details. We therefore test for cointegration. Pedroni (1999) suggests a suite of 7 tests designed to test the null hypothesis of no cointegration in dynamic panels with multiple regressors and with a rank equal to 1 . The first four tests are based on the within panel estimator (see Hsiao, 1986), and are listed as tests 1-4 in Table 1. The last three tests are labelled Group Mean Panel Tests by Pedroni, and are calculated by pooling along the between dimension. The test statistics are calculated using RATS $^{8}$ and presented in the same order as in Pedroni (1999).

While macro panels typically exhibit cross-sectional dependence, the Pedroni panel data cointegration tests all assume cross-country independence. As shown by Banerjee, Marcellino and Osbat (2004, 2005) using Monte Carlo simulations, falsely assuming cross-sectional independence causes severe size distortions. We have included common time dummies to capture some of the common shocks and thus to some extent correct for this form of cross-sectional dependence in the panel. The time dummies are not necessarily present in a preferred dynamic model. The tests for cointegration are conducted in a static regression setting.

The Pedroni-tests in Table 1 show that the null of no cointegration is generally not rejected, hence the formal evidence in favour of cointegration is weak. However, since the estimated coefficients in our models - both in the OE-NPC and the ICM - resembles quite well the findings in single-country analysis and the cointegration tests have low power, we continue our modelling strategy assuming that the long-run

${ }^{8}$ RATS v. 5.00, Doan (2000). Many thanks to professor Peter Pedroni for providing us with the RATS codes used to calculate the relevant test statistics. 
variables are in fact cointegrated. After all, our most important benchmark is the existing literature cited previously.

Fifth and finally, while the GMM estimation with spherical errors is a useful reference point, the hetogeneity of panel data makes it adviseable to rely most on evicence from methods that control for heterocedasticity and error dependence in the panel regressions. Therefore, we have estimated the model (10), and the NPC that it contains, using GMM with Cross-Section SUR (PCSE) corrections of standard errors and covariances. The Cross-Section SUR estimator is robust to both panel heteroscedasticity and contemporaneous correlations in the errors. ${ }^{9}$

\section{Testing the New Keynesian Phillips Curve on OECD Data}

Table 2 reports the estimation results for the OECD inflation models. NPC1 is the empirical equivalent to equation (2) with real marginal costs measured in accordance with equation (3) above, i.e., by the wage share of gross value added, $w s_{i, t}$. NPC2 uses unit labour costs deflated by the consumer price index. However, the estimates in Table 2 show that this distinction has virtually no effect on the estimation results. NPC3 is the empirical equivalent to equation (6) above, and is a reparameterisation of equation (2) with the additional assumption of a constant share of import prices in the consumer price index. The Minimum nesting model is the encompassing model equivalent to equation (9) above, i.e. the estimated equilibrium correction model, which under the assumption of a constant import share encompasses both the NPC and the ICM interpretation.

As noted above, the models are estimated using GMM with Cross-Section SUR corrections of standard errors and covariances, where $\Delta p_{i, t+1}, \Delta u c_{i, t}$ and $\Delta\left(p i_{i, t}-\right.$ $\left.p_{i, t}\right)$ are treated as endogenous explanatory variables. This estimation technique corrects for both panel heteroscedasticity and contemporaneous correlations in the errors. The following variables are used as instruments in all models: $\Delta p_{i, t-2}, \Delta p i_{i, t-1}$, $\Delta p o_{i, t-1}, \Delta u c_{i, t-1}$ and $w s_{i, t-1}$, the unemployment rate lagged twice $\left(U R_{t-2}\right)$, current and lagged gross replacement rate $(B R R)$ and an index of employment protection $(E P) .\left(u l c_{i, t-1}-p i_{i, t-1}\right)$ and $\left(u l_{i, t-1}-p_{i, t-1}\right)$ are additional instruments in the two models NPC1 and NPC2.

As can be seen, the results for NPC1 and NPC2 correspond closely to the typical hybrid NPC model. In fact, the first three typical features listed in section 2 are clearly recognizable. Both the lagged and leading inflation terms have significant coefficients; the sum of the coefficients cannot be statistically distinguished from unity, and the lead term gets the highest estimated coefficient. The only anomaly is the insignificance of the wage-share coefficients, which contradicts the typical NPC feature 4 .

That the panel data results for the NPC are corroborating the typical finding on US and euro-area data, as well as on data of other countries may be taken as

\footnotetext{
${ }^{9}$ For further details on this estimation procedure see the EViews User's Guide, Quantity Micro Software (2005, Ch. 29).
} 
Table 2: GMM Estimation Results for an OECD Panel Data Set. Cross-Section SUR Correction of Second Moments

\begin{tabular}{|c|c|c|c|c|}
\hline 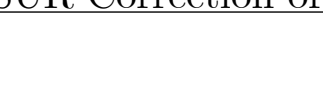 & NPC1 & NPC2 & NPC3 & $\begin{array}{l}\text { Minimum } \\
\text { nesting model }\end{array}$ \\
\hline$\Delta p_{i, t+1}$ & $\begin{array}{l}0.59 \\
(0.08)\end{array}$ & $\begin{array}{l}0.59 \\
(0.08)\end{array}$ & $\begin{array}{l}0.50 \\
(0.08)\end{array}$ & $\begin{array}{l}0.04 \\
(0.11)\end{array}$ \\
\hline$\Delta p_{i, t-1}$ & $\begin{array}{l}0.44 \\
(0.05)\end{array}$ & $\begin{array}{l}0.43 \\
(0.05)\end{array}$ & $\begin{array}{l}0.44 \\
(0.05)\end{array}$ & $\begin{array}{l}0.43 \\
(0.04)\end{array}$ \\
\hline$w s_{i, t}$ & $\begin{array}{c}-0.007 \\
(0.015)\end{array}$ & & & \\
\hline$\left(u l c_{i, t}-p_{i, t}\right)$ & & $\begin{array}{l}0.007 \\
(0.012)\end{array}$ & & \\
\hline$\left(u l c_{i, t-1}-p_{i, t-1}\right)$ & & & $\begin{array}{l}0.021 \\
(0.013)\end{array}$ & $\begin{array}{l}0.055 \\
(0.016)\end{array}$ \\
\hline$\left(u l c_{i, t-1}-p i_{i, t-1}\right)$ & & & $\begin{array}{l}-0.013 \\
(0.006)\end{array}$ & $\begin{array}{c}-0.021 \\
(0.006)\end{array}$ \\
\hline$\Delta u l c_{i, t}$ & & & $\begin{array}{c}0.008 \\
(--)\end{array}$ & $\begin{array}{l}0.33 \\
(0.06)\end{array}$ \\
\hline$\Delta\left(p i_{i, t}-p_{i, t}\right)$ & $\begin{array}{l}0.05 \\
(0.02)\end{array}$ & $\begin{array}{l}0.05 \\
(0.02)\end{array}$ & $\begin{array}{l}0.06 \\
(0.02)\end{array}$ & $\begin{array}{l}0.11 \\
(0.02)\end{array}$ \\
\hline$\Delta p o_{i, t}$ & $\begin{array}{l}0.004 \\
(0.005)\end{array}$ & $\begin{array}{l}0.004 \\
(0.005)\end{array}$ & $\begin{array}{l}0.006 \\
(0.005)\end{array}$ & $\begin{array}{l}0.006 \\
(0.003)\end{array}$ \\
\hline$\Delta V A T_{i, t}$ & $\begin{array}{l}0.004 \\
(0.001)\end{array}$ & $\begin{array}{l}0.004 \\
(0.001)\end{array}$ & $\begin{array}{l}0.004 \\
(0.001)\end{array}$ & $\begin{array}{l}0.003 \\
(0.001)\end{array}$ \\
\hline \# observ & 567 & 567 & 567 & 567 \\
\hline$\hat{\sigma} \cdot 100$ & 1.31 & 1.30 & 1.25 & 1.08 \\
\hline$\chi_{\text {ival }}^{2}$ & $18.0[0.035]$ & $17.7[0.038]$ & $15.2[0.055]$ & $10.0[0.187]$ \\
\hline$N_{\mathrm{AR}-1}$ & $-9.08[0.000]$ & $-9.03[0.000]$ & $-8.06[0.000]$ & $-1.46[0.15]$ \\
\hline$N_{\mathrm{AR}-2}$ & $-6.66[0.000]$ & $-6.61[0.000]$ & $-5.98[0.000]$ & $-0.52[0.60]$ \\
\hline
\end{tabular}

Notes: Square brackets, [..], contain p-values, heteroscedasticity consistent standard errors are in parentheses, (..). $\hat{\sigma}$ denotes the estimated residual standard error. $\chi_{\text {ival }}^{2}$ denotes the Sargan Sargan (1964) specification test which is $\chi^{2}$ distributed under the null of valid instruments (degrees of freedom are 10,10,9 and 8 respectively). $N_{\mathrm{AR}-1}$ and $N_{\mathrm{AR}-2}$ have a standard normal distribution under the null of no 1st and 2nd order autoregressive errors, respectively. 
an indication that the potential econometric problems discussed in section 4 are not too large.

Among the four model, it is the Minimum nesting model which is most likely to be affected by weak instruments problems, since it has two instruments less than NPC1 and NPC2, i.e., $\left(u l c_{i, t-1}-p_{i, t-1}\right)$ and $\left(u l c_{i, t-1}-p i_{i, t-1}\right)$. Hence we first test the strength of the other 13 instruments used in the Minimum nesting model. The result is $F=57$, which is much higher than the rule-of-thumb of 10, see Stock et al. (2002). As for NPC1 and NPC2, the 'first stage regression' for those models includes $\left(u l c_{i, t-1}-p_{i, t-1}\right)$ and $\left(u l c_{i, t-1}-p i_{i, t-1}\right)$. In line with this, the test statistic for instrument irrelevance is $F=76$ for NPC1 and NPC2. Incidentally, Bårdsen et al. (2004) report $F=71$ for their re-estimation of the euro area NPC.

Since the typical features of NPC is also present in NPC3 we can investigate the encompassing capabilities of the NPC by considering the coefficients (and standard errors) of $\left(u l c_{i, t-1}-p_{i, t-1}\right),\left(u l c_{i, t-1}-p i_{i, t-1}\right), \Delta u l c_{i, t}$ and $\Delta p i_{i, t}$ in NPC3 and in the Minimum nesting model. It is evident that $H_{0}^{a}: \beta_{3}=\beta_{1}+\beta_{2}$ will be rejected at any reasonable level of significance. For example, the estimated coefficient of $\left(u c_{i, t-1}-p_{i, t-1}\right)$ in the general model is 0.33 , which is 10 times the size in the NPC model. Hence on this test, the NPC does not parsimoniously encompass the minimum nesting model. Conversely, the hypothesis $H_{0}^{c}: \alpha^{f}=0$ is not rejected, as can be seen directly from the estimation results for the Minimum nesting model, implying that the standard ICM, without a lead in inflation, does parsimoniously encompass the unrestricted (nesting) model.

The diagnostic tests at the bottom are also of interest for those who want to test the NPC as a valid econometric model. First, Sargan's test statistic $\chi_{\text {ival }}^{2}$, which has an interpretation as an encompassing test, is significant for NPC1 and NPC2, and barely insignificant for NPC3. As discussed in section 3, this is consistent with ICM being the valid model. Second, there is significant residual autocorrelation in NPC1, NPC2 and NPC3, but not in the Minimum nesting model. In sum, the results for the Minimum nesting model suggests that inflation equilibrium corrects with respect to an open economy long-run price equation. Hence, our interpretation of the cointegration tests in Table 1 is supported by the results for the dynamic econometric Minimum nesting model in Table 2.

In Bjørnstad and Nymoen (2008) we report a similar table for standard GMM estimation with spherical disturbances. ${ }^{10}$ The point estimates of the coefficients of all four models are practically the same in the simpler estimation, while the standard errors of the coeffients are somewhat bigger, as can be expected. In fact, the only notable difference between the two sets of results is that without the SUR corrections, the $\chi_{\text {ival }}^{2}$ statistic is rejecting the three NPCs at much lower levels of significance than in Table 2.

Since the NPC model according to NPC1, NPC2 and NPC3 fails to meet the standards of a well specified econometric model, it is not a surprise that the wageshare variables have insignificant effects in these models, i.e. violation of the typical NPC feature 4 in section 2. In the Minimum nesting model the equilibrium correction variables have in contrast highly significant effects. This means that real variables are expected to influence on the inflation process, even though the insignificance of

${ }^{10}$ See Table 3 in Bjørnstad and Nymoen (2008). 
the wage-share in estimated NPC models may indicate the opposite.

\section{Conclusion}

GGL claim that the NPC represents a significant advance in inflation modelling which finally substantiates the dominance of forward-looking behavior in price adjustment. In this paper we have lifted the empirical testing of the NPC model from the relatively calm waters of US and euro area data to the vast data ocean represented by a panel data set from 20 OECD countries. We are able replicate the typical features of estimated NPC model - thus the New Keynesian Phillips curve appears to hold its ground on the panel data set..

However, a main insight of our analysis is that researchers will be able to empirical confirm the NPC in the way we have demonstrated, even in the case where the NPC it is not an encompassing model. This is true for country data, or area data, as well as panel data. Hence, an encompassing approach is a necessary ingredient in the empirical assessment of the NPC. We find that the standard NPC model is encompassed by an existing model known as the imperfect competition model, ICM, of wage and price setting. Specifically, our analysis shows that the expected rate of future inflation and the wage-share serve as replacements for ICM specific equilibrium correction terms. Adding these terms to the NPC model critically affect the estimated coefficient of the forward term: not only is the coefficient insignificant, the point estimate is also close to zero.

The search of a congruent and encompassing model with expected future inflation as an explanatory variable must therefore go on, since the existing NPCs do not achieve these hallmarks of credibility. While awaiting such new evidence, models of the ICM type without feed-forward variables, may be regarded as more structural equations in the meaning of being theory consistent relationships with relatively constant parameters and with an encompassing capability among their merits.

\section{A Appendix: Data Definitions and Sources}

The data consist of annual time series from as early as 1960 for some countries and up to 2004 for all the 20 OECD countries given in the table below. Some of the variables do not exist for the whole period, and similarly some countries' variables are not available. Consequently, we use an unbalanced panel data set.

Most of the data used in this paper is retrieved from or constructed by using the Organization for Economic Cooperation and Development (OECD) Economic Outlook and Main Economic Indicators (MEI) Databases. ${ }^{11}$ This should help ensuring consistency in the data set.

Description of the variables

$P$ : Consumer prices. $P$ is a consumer price index, $2000=100$, retrieved from the Main Economic Indicator (MEI) OECD database.

\footnotetext{
${ }^{11}$ By using Xvision Fame 8.0.2, a programme licensed by SunGard Data Management Solutions.
} 
Table 3: Listing of countries in the data set.

Name of country Number in database

\begin{tabular}{lc}
\hline Australia & 1 \\
Austria & 2 \\
Belgium & 3 \\
Canada & 4 \\
Denmark & 5 \\
Finland & 6 \\
France & 7 \\
Germany & 8 \\
Ireland & 9 \\
Italy & 10 \\
Japan & 11 \\
Netherlands & 12 \\
New Zealand & 13 \\
Norway & 14 \\
Portugal & 15 \\
Spain & 16 \\
Sweden & 17 \\
Switzerland & 18 \\
UK & 19 \\
USA & 20
\end{tabular}

PI : Price of imports. The ratio of import value and import volume, both in domestic currency, is used as a proxy for the price of imports. The series are retrieved from the MEI OECD database.

PO : Price of oil. The world dated price of Brent crude oil measured in USD per barrel is retrieved from the MEI OECD database.

$U R$ : Rate of unemployment. The OECD standardized unemployment rates give the number of unemployed persons as a percentage of the civilian labour force. The series are retrieved from the MEI OECD database.

$U L C$ : Unit Labour Costs. ULC is an index of unit labour costs $(2000=100)$ and is retrieved from the MEI OECD.

$V A T$ : Indirect tax rate. This is standard VAT rates in per cent for the different OECD countries. VAT rates for the EU is retrieved from DOC/1635/2005 - EN. VAT rates for Japan, New Zealand, Norway, Canada and Australia is obtained from the countries' respective national bureaus of statistics. VAT rates for the United States are missing and are therefore assumed to be constant in the analysis.

EP: Employment protection. The data comprise an index of the degree of employment protection, and are provided by Dr. Luca Nunziata, Nuffield College, University of Oxford, UK, see Nunziata (2005). The series are extended with the 1995 value for the years 1996-2004.

BBR: Benefit Replacement Ratio. The data comprise an index of unemployment benefits in per cent of the average wage level, and are provided by Dr. Luca Nun- 
ziata, Nuffield College, University of Oxford, UK, see Nunziata (2005). The series are extended with the 1995 value for the years 1996-2004. 


\section{References}

Aldrich, J. (1995). Correlations Genuine and Spurious in Pearson and Yule. Statistical Science, 10(4), 364-376.

Baltagi, B. (1995). Econometric Analysis of Panel Data. Wiley.

Banerjee, A., M. Marcellino and C. Osbat (2004). Some Cautions on the Use of Panel Methods for Integrated Series of Macro-Economic Data. Econometrics Journal, 7, 322-340.

Banerjee, A., M. Marcellino and C. Osbat (2005). Breaking Panel Data Cointegration. Mimeo.

Bårdsen, G., Ø. Eitrheim, E. S. Jansen and R. Nymoen (2005). The Econometrics of Macroeconomic Modelling. Oxford University Press, Oxford.

Bårdsen, G., P. G. Fisher and R. Nymoen (1998). Business Cycles: Real Facts or Fallacies? In Strøm, S. (ed.), Econometrics and Economic Theory in the 20th Century: The Ragnar Frisch Centennial Symposium, no. 32 in Econometric Society Monograph Series, chap. 16, 499-527. Cambridge University Press, Cambridge.

Bårdsen, G., E. S. Jansen and R. Nymoen (2004). Econometric evaluation of the New Keynesian Phillips curve. Oxford Bulletin of Economics and Statistics, 66, 671-686. Supplement.

Bårdsen, G. and R. Nymoen (2003). Testing Steady-State Implications for the NAIRU. Review of Economics and Statistics, 85, 1070-1075.

Bårdsen, G. and R. Nymoen (2008). Macroeconometric Modelling for Policy. Fortchoming in Mills T.C. and K. Patterson (eds), Palgrave Handbook of Econometrics Vol 2, Palgrave Mac-Millan, 2008.

Batini, N., B. Jackson and S. Nickell (2005). An Open-Economy New Keynesian Phillips Curve for the U.K. Journal of Monetary Economics, 52, 1061-1071.

Bjørnstad, R. and R. Nymoen (2008). The New Keynesian Phillips Curve tested on OECD panel data. Discussion Paper 2008-4, February 11, 2008, Economics Discussion Papers, The Open-Access, Open Assessment E-Journal, www.economicsejournal.org/discussionpapers.

Blake, D. (1991). The Estimation of Rational Expectations Models: A survey. Journal of Economic Studies, 18(3), 31-70.

Boug, P., A. Cappelen and A. Swensen (2006). Expectations and Regime Robustness in Price Formation: Evidence from Vector Autoregressive Models and Recursive Methods. Discussion Paper 460, Statistics Norway.

Calvo, G. A. (1983). Staggered prices in a utility maximizing framework. Journal of Monetary Economics, 12, 383-398. 
Clarida, R., J. Galí and M. Gertler (1999). The Science of Monetary Policy: A New Keynesian Perspective. Journal of Economic Literature, 37(4), 1661-1707.

Fanelli, L. (2008). Testing the New Keynesian Phillips Curve Through Vector Autoregressive Models: Results from the Euro Area. Oxford Bulletin of Economics and Statistics, 70(1), 53-66.

Fuhrer, J. (2006). Intrinsic and Inherited Inflation Persistence. International Journal of Central Banking, 2, 49-86.

Galí, J. and M. Gertler (1999). Inflation Dynamics: A Structural Econometric Analysis. Journal of Monetary Economics, 44 (2), 233-258.

Gali, J., M. Gertler and J. Lopez-Salido (2005). Robustness of the Estimates of the Hybrid New Keynesian Phillips Curve. Journal of Monetary Economics, 52, $1107-1118$.

Galí, J., M. Gertler and J. D. López-Salido (2001). European Inflation Dynamics. European Economic Review, 45, 1237-1270.

Gordon, R. J. (1997). The Time-Varying NAIRU and its Implications for Economic Policy. Journal of Economic Perspectives, 11(1), 11-32.

Hendry, D. F. (1988). The Encompassing Implications of Feedback versus Feedforward Mechanisms in Econometrics. Oxford Economic Papers, 40, 132-149.

Hendry, D. F. (1995). Dynamic Econometrics. Oxford University Press, Oxford.

Judsen, R. and A. Owen (1999). Estimataing Dynamic Panel Data Models: A Guide for Macroeconomists. Economic Letters, 65, 9-15.

Juselius, M. (2007). A Cointegration Approach to Topics in Empirical Macroeconomics. Ph.D. thesis, Swedish School og Economics and Business Administration, Finland.

Linde, J. (2005). Estimating New-Keynesian Phillips Curves: A Full Information Maximum Likelihood Approach. Journal of Monetary Economics, 52, 11351149 .

Mavroeidis, S. (2004). Weak identification of forward-looking models in monetary economics. Oxford Bulletin of Economics and Statistics, 66, 609-635. Supplement.

Nickell, S. (1981). Biases in Dynamic Models with Fixed Effects. Econometrica, 49, 1417-1426.

Nunziata, L. (2005). Institutions and Wage Determination: A Multi-Country Approach. Oxford Bulletin of Economics and Statistics, 67(4), 435-466.

Nymoen, R. (1991). A Small Linear Model of Wage- and Price-Inflation in the Norwegian Economy. Journal of Applied Econometrics, 6, 255-269. 
Pedroni, P. (1999). Critical Values for Cointegration Tests in Heterogeneous Panels with Multiple Regressors. Oxford Bulletin of Economics and Statistics, 61, 653670 .

Pesaran, H. and R. Smith (1995). Estimating Long-Run Relationships from Dynamic Heterogeneous Panels. Journal of Econometrics, 68, 79-130.

Pesaran, M. (1987). The Limits to Rational Expectations. Basil Blackwell, Oxford.

Phelps, E. S. (1978). Disinflation without recession: Adaptive guideposts and monetary policy. Weltwirtschaftliches Archiv, 100, 239-265.

Roberts, J. M. (1995). New Keynesian economics and the Phillips curve. Journal of Money, Credit and Banking, 27, 975-984.

Rotemberg, J. J. (1982). Sticky prices in the United States. Journal of Political Economy, 90, 1187-1211.

Rudd, J. and K. Whelan (2005). New tests of the New Keynesian Phillips curve. Journal of Monetary Economics. Forthcoming.

Sargan, J. D. (1964). Wages and Prices in the United Kingdom: A Study of Econometric Methodology. In Hart, P. E., G. Mills and J. K. Whitaker (eds.), Econometric Analysis for National Economic Planning, 25-63. Butterworth Co., London.

Sargan, J. D. (1980). A Model of Wage-Price Inflation. Review of Economic Studies, $47,113-135$.

Stock, J. H., J. H. Wright and M. Yogo (2002). A Survey of Weak Instruments and Weak Identification in Generalized Method of Moments. Journal of Business and Economic Statistics, 20(4), 518-529.

Taylor, J. B. (1979). Staggered wage setting in a macro model. American Economic Review, 69, 108-113.

Taylor, J. B. (1980). Aggregate dynamics and staggered contracts. Journal of Political Economy, 88, 1-23. 
Please note:

You are most sincerely encouraged to participate in the open assessment of this article. You can do so by either rating the article on a scale from 1 (bad) to 5 (excellent) or by posting your comments.

Please go to:

www.economics-ejournal.org/economics/journalarticles/2008-23

The Editor 